\title{
Primary leiomyosarcoma of a horseshoe kidney in a woman with Turner syndrome: a case report
}

\author{
Toshikazu Tanaka ${ }^{1,2}$, Takuya Koie $^{2 *}$, Ikuya Iwabuchi', Masaru Ogasawara', Toshiaki Kawaguchi ${ }^{1}$ and Chikara Ohyama $^{2}$
}

\begin{abstract}
Background: Turner syndrome is characterized by complete or partial X-chromosome monosomy and has various clinical features, including horseshoe kidney. Leiomyosarcoma is an extremely rare tumor that accounts for only $0.1 \%$ of all invasive renal tumors.

Case presentation: A 50-year-old Japanese woman presented at a community hospital with a chief complaint of abdominal pain. Computed tomography revealed a horseshoe kidney with a hypovascular tumor $(\mathrm{size}, 9 \times 7 \mathrm{~cm})$ showing calcification in the upper pole of the right kidney. Open right heminephrectomy and division of the isthmus were performed. Histological examination revealed alternating fascicles of spindle cells with blunt ended non-tapering nuclei and eosinophilic cytoplasm. The tumor had high mitotic activity with a mitotic count of 8 mitoses/10 high-power fields. On the basis of these findings, we diagnosed the patient as having leiomyosarcoma.
\end{abstract}

Conclusion: Primary leiomyosarcoma of the horseshoe kidney in a patient with Turner syndrome is a very rare occurrence.

Keywords: Leiomyosarcoma, Turner syndrome, Horseshoe kidney

\section{Background}

Turner syndrome (TS) affects approximately 1 in 2,000 live-born girls [1]. This condition is characterized by complete or partial X-chromosome monosomy. The typical clinical features are short stature, ovarian dysgenesis with concomitant primary amenorrhea, and lymphedema. Horseshoe kidney has been observed in approximately $30 \%$ of patients with TS [2]. Although primary leiomyosarcoma is the most common de novo renal sarcoma of the kidney, it is an extremely rare entity that accounts for only $0.1 \%$ of all invasive renal tumors [3]. Here, we report a unique case of leiomyosarcoma arising in the horseshoe kidney of a patient with TS.

\section{Case presentation}

A 50-year-old Japanese woman presented at a community hospital with a chief complaint of abdominal pain. Computed tomography revealed a horseshoe kidney (Figure 1)

\footnotetext{
* Correspondence: goodwin@cc.hirosaki-u.ac.jp

${ }^{2}$ Department of Urology, Hirosaki University Graduate School of Medicine, 5 Zaifucho, Hirosaki 036-8562, Japan

Full list of author information is available at the end of the article
}

with a hypovascular tumor (size, $9 \times 7 \mathrm{~cm}$ ) showing calcification in the upper pole of the right kidney (Figure 2). The tumor was clinically diagnosed as a right renal cell carcinoma (RCC) and was classified as cT3aNOM0, according to the tumor-node-metastasis system [4]. Open right heminephrectomy and division of the isthmus were performed. Macroscopic examination revealed a solid, circumscribed, and yellowish-white tumor (size, $9 \times 7 \mathrm{~cm}$ ) in the upper pole of the resected kidney (Figure 3). Histological examination revealed alternating fascicles of spindle cells with blunt ended non-tapering nuclei and eosinophilic cytoplasm (Figure 4). The tumor had high mitotic activity with a mitotic count of 8 mitoses/10 high-power fields. Immunohistochemical analysis revealed that the tumor cells were strongly positive for alpha-smooth muscle actin (Figure 5), desmin, vimentin, and Ki-67 (Figure 6). On the basis of these findings, we diagnosed the patient as having stage pT2aNOMO leiomyosarcoma.

The patient was asymptomatic and disease free at 6 months after the diagnosis.

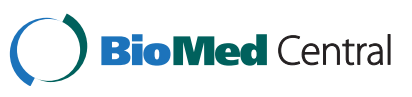

(c) 2014 Tanaka et al.; licensee BioMed Central Ltd. This is an Open Access article distributed under the terms of the Creative Commons Attribution License (http://creativecommons.org/licenses/by/2.0), which permits unrestricted use, distribution, and reproduction in any medium, provided the original work is properly credited. The Creative Commons Public Domain Dedication waiver (http://creativecommons.org/publicdomain/zero/1.0/) applies to the data made available in this article, unless otherwise stated. 


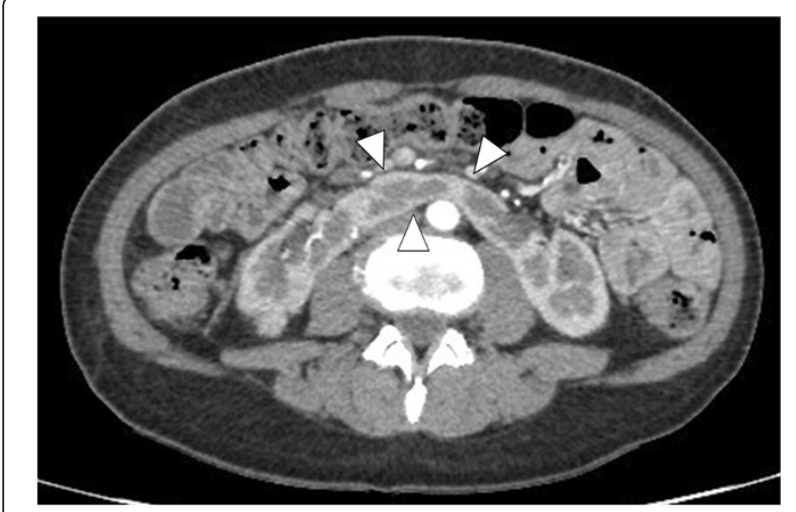

Figure 1 Enhanced abdominal computed tomography. Abdominal computed tomography revealed a horseshoe kidney. The arrowheads indicated the isthmus of the horseshoe kidney.

\section{Conclusions}

To the best of our knowledge, this is the first reported case of primary leiomyosarcoma arising in a horseshoe kidney in a patient with TS.

The risk of cancer in patients with TS has been established. The overall risk of cancer is similar to that in the general population [5]. However, in patients with TS, sitespecific risks were significantly increased for meningeal tumors, childhood brain tumors, bladder and urethral cancer, and ocular cancer and significantly decreased for breast cancer [5]. Therefore, the hormonal abnormalities associated with TS might affect the risk of hormonerelated cancers, and the chromosomal abnormality itself might affect the cancer risk. The cancer risk was potentially related to the absence of one or more genes on the $\mathrm{X}$ chromosome that escape $\mathrm{X}$-inactivation [6]. The $\mathrm{X}$

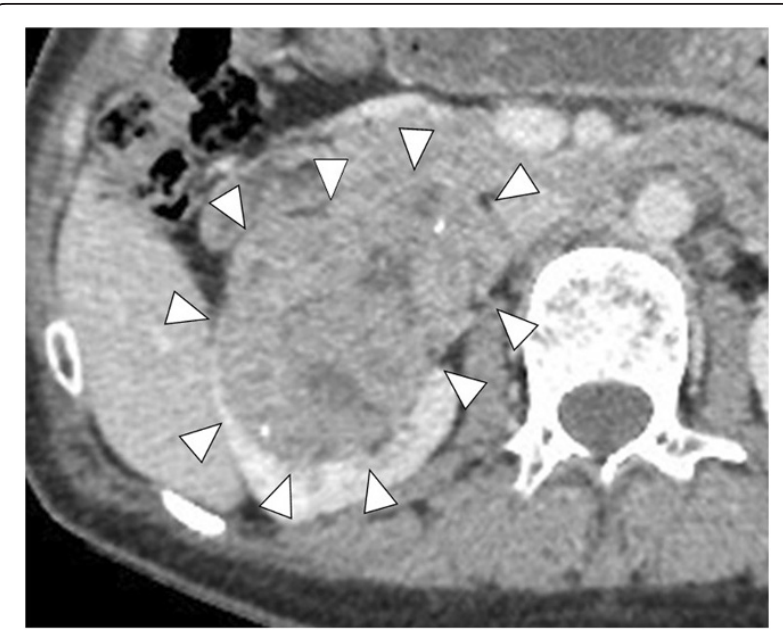

Figure 2 Enhanced abdominal computed tomography.

Abdominal computed tomography revealed a hypovascular tumor, measuring $9 \times 7 \mathrm{~cm}$, in the upper pole of the right

kidney (arrowheads).

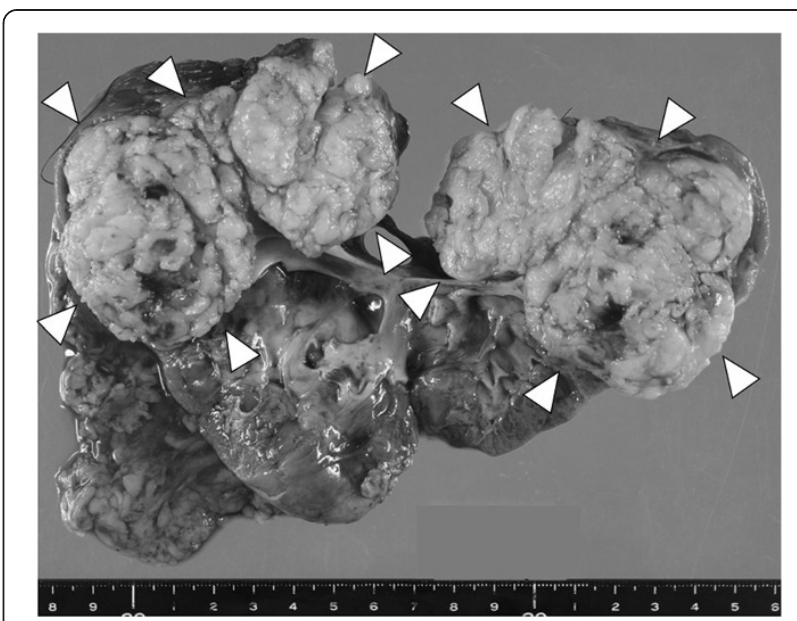

Figure 3 Macroscopic findings. Macroscopic examination revealed a solid, circumscribed, and yellowish-white tumor, measuring $9 \times 7 \mathrm{~cm}$ in size, in the upper pole of the resected kidney (arrowheads).

chromosome has many cancer-related genes [7], and allelic losses from the $\mathrm{X}$ chromosome have been noted in several malignancies $[8,9]$. Such losses suggest that the presence of one or more tumor-suppressor or DNA-repair genes on the $\mathrm{X}$ chromosome is relevant to the etiology of these tumors [5].

The phenotype of TS is highly variable, with a wide variety of clinical conditions. Renal and/or collecting system malformations, including horseshoe kidney, renal malrotation, and collecting system malformations, have been observed in $30-40 \%$ of patients with TS [2]. Although most structural anomalies may initially be asymptomatic, there may be a high risk of hypertension, urinary tract infection, and hydronephrosis [2]. The incidence of tumors in a horseshoe kidney is approximately 3-4 times higher in patients with TS than in the general population [10]. Therefore, it has been suggested to be caused by chronic obstruction, lithiasis, and infection. RCC is the most common neoplasm associated with horseshoe kidney and is mostly found adjacent to or within the isthmus [11]. Furthermore, horseshoe kidney is associated with a 2 -fold increase in the relative risk of Wilms tumor and a 3 - to 4-fold increase in the risk of transitional cell carcinoma [12].

Primary renal sarcomas are rare in adults and account for approximately $1 \%$ of all primary renal malignancies, whereas leiomyosarcoma constitute approximately 50$60 \%$ of all cases of renal sarcoma [13]. Leiomyosarcoma of the kidney most likely arises from the renal capsule, smooth muscle fibers of the renal pelvis, sphincter ring around the renal papilla, and internal blood vessels [14]. In contrast, the vast majority of malignant spindle cell tumors of the kidney represent a component of a sarcomatoid carcinoma [13]. Sarcomatoid carcinomas arise from either renal cell carcinoma or, less commonly, urothelial 


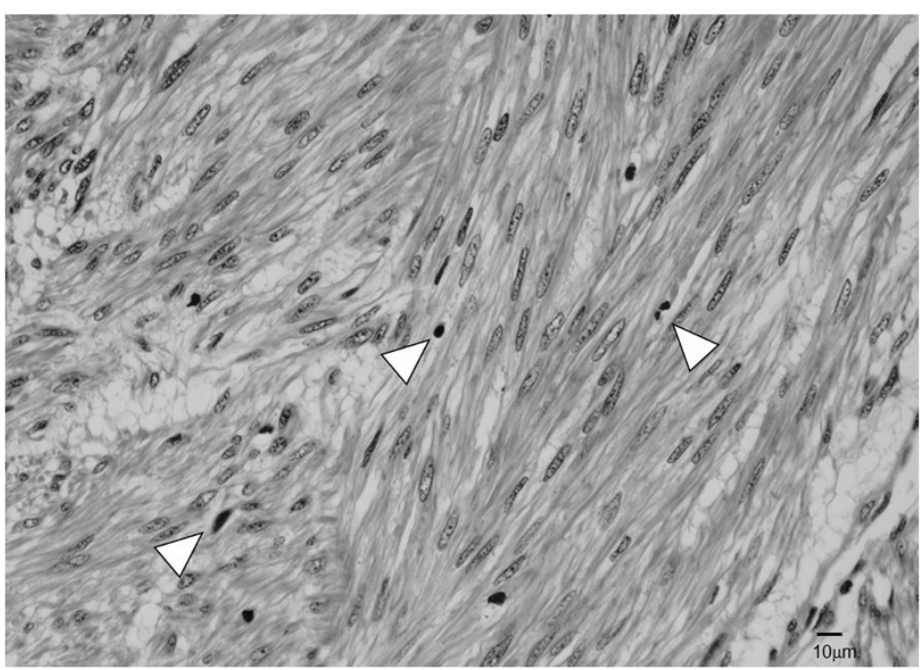

Figure 4 Hematoxylin-eosin stained section of the tumor. The cells had alternating fascicles of spindle cells with blunt ended non-tapering nuclei and eosinophilic cytoplasm (arrowheads) (magnification, 200x).

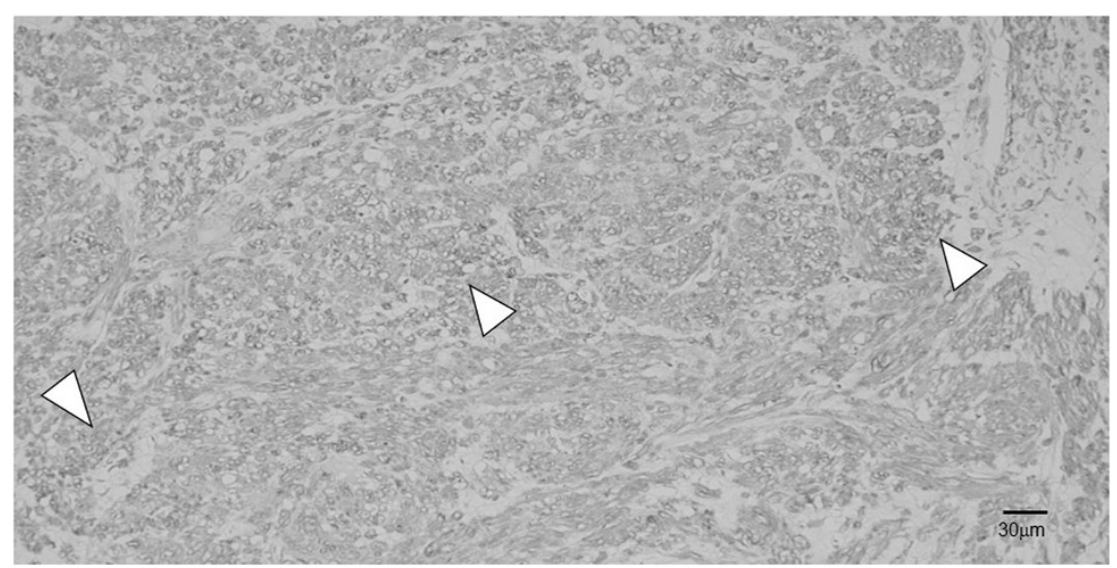

Figure $\mathbf{5}$ Section of the tumor stained for alpha-smooth muscle actin. The tumor cells were strongly positive for alpha-smooth muscle actin (arrowheads) (magnification, 100x).

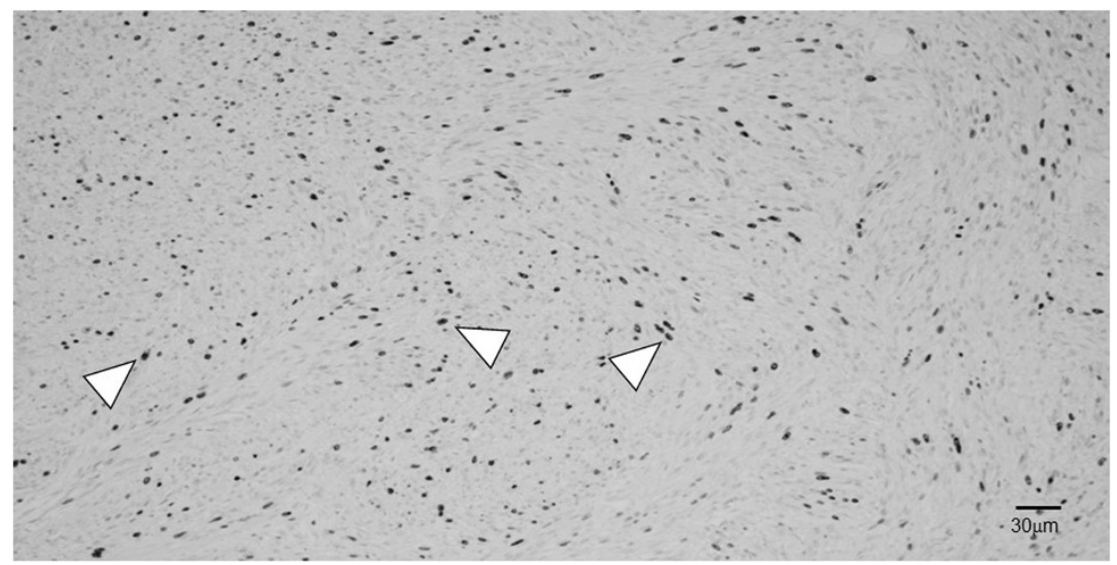

Figure 6 Section of the tumor stained for Ki-67. The tumor cells were strongly positive for Ki-67 (arrowheads) (magnification, 100x). 
carcinomas of the renal pelvis [15]. Although the spindle cell component consisting of sarcomatoid RCC is often positive for epithelial markers, leiomyosarcoma is very rarely positive for keratins [16].

A few large series on primary leiomyosarcoma of the kidney with an analysis of the prognosis have been reported. Kendal analyzed the population-based surveillance, epidemiology, and end results (SEER) registry and reported on the survival of 112 patients with renal leiomyosarcomas [3]. On the basis of the SEER data, the median overall survival (OS) was 25 months and the 5-year OS rate was $25 \%$. The tumor stage and age at diagnosis were independent predictive factors for OS [3].

In conclusion, primary leiomyosarcoma of the horseshoe kidney in a patient with TS is a very rare occurrence. It is important to remember that this unusual variant of renal leiomyosarcoma has the potential for aggressive behavior, which can lead to metastasis.

\section{Consent}

Written informed consent was obtained from the patient for publication of this Case Report and any accompanying images. A copy of the written consent is available for review by the Editor-in-Chief of this journal.

\section{Abbreviations}

TS: Turner syndrome; RCC: Renal cell carcinoma; SEER: Surveillance,

epidemiology, and end results; OS: Overall survival.

\section{Competing interests}

The authors declare that they have no competing interests.

\section{Authors' contributions}

$Y T$ and TK were involved in drafting the manuscript. TK performed the clinical follow-up and contributed to manuscript preparation. KO and II performed the surgery. TK and CO were responsible for the concept and design of this study, interpretation of the data, and critical revision of the manuscript. All authors read and approved the final manuscript.

\section{Author details}

'Department of Urology, Aomori Prefectural Central Hospital, 2-1-1

Tsukurimichi, Aomori 030-8553, Japan. ${ }^{2}$ Department of Urology, Hirosaki

University Graduate School of Medicine, 5 Zaifucho, Hirosaki 036-8562, Japan.

Received: 31 January 2014 Accepted: 28 July 2014

Published: 4 August 2014

\section{References}

1. Stochholm K, Juul S, Juel K, Naeraa RW, Gravholt CH: Prevalence, incidence, diagnostic delay, and mortality in Turner syndrome. J Clin Endocrinol Metab 2006, 91:3897-3902

2. Bilge I, Kayserili H, Emre S, Nayir A, Sirin A, Tukel T, Bas F, Kilic G, Basaran S, Gunoz H, Apak M: Frequency of renal malformations in Turner syndrome: analysis of 82 Turkish children. Pediatr Nephrol 2000, 14:1111-1114.

3. Kendal WS: The comparative survival of renal leiomyosarcoma. Can J Urol 2007, 14:3435-3442.

4. Sobin LH: TNM Classification of Malignant Tumors. New York: Wiley-Liss; 2002.

5. Schoemaker M, Swerdlow A, Higgins CD, Wright AF, Jacobs PA: Cancer incidence in women with Turner syndrome in Great Britain: a national cohort study. Lancet Oncol 2008, 9:239-246.

6. Brown CJ, Greally JM: A stain upon the silence: genes escaping $X$ inactivation. Trends Genet 2003, 19:432-438.
7. Liao DJ, Du QQ, Yu BW, Grignon D, Sarkar FH: Novel perspective: focusing on the X chromosome in reproductive cancers. Cancer Invest 2003, 21:641-658

8. Indsto JO, Nassif NT, Kefford RF, Mann GJ: Frequent loss of heterozygosity targeting the inactive $\mathrm{X}$ chromosome in melanomas. Clin Cancer Res 2003, 9:6476-6482.

9. Cheng L, MacLennan GT, Pan CX, Jones TD, Moore CR, Zhang S, Gu J, Patel NB, Kao C, Gardner TA: Allelic loss of the active $X$ chromosome during bladder carcinogenesis. Arch Pathol Lab Med 2004, 128:187-190.

10. Ying-Long S, Yue-Min X, Hong X, Xiao-Lin X: Papillary renal cell carcinoma in the horseshoe kidney. Acta South Med J 2010, 103:1272-1274.

11. Alamer A: Renal cell carcinoma in a horseshoe kidney: radiology and pathology correlation. J Clin Imaging Sci 2013, 3:12.

12. Buntley D: Malignancy associated with horseshoe kidney. Urology 1976, 8:146-148.

13. Moazzam M, Ather MH, Hussainy AH: Leiomyosarcoma presenting as a spontaneous ruptured renal tumor-case report. BMC Urol 2002, 192:13.

14. Mondoumi SM, En-Nia I, Rioux-Leclerq N, Guille F, Lobel B: Leiomyosarcoma of the renal pelvis. Scand J Urol Nephrol 2001, 35:425-427.

15. de Peralta-Venturina M, Moch H, Amin M, Tamboli P, Hailemarian S, Mihatsch M, Javidan J, Stricker H, Ro JY, Amin MB: Sarcomatoid differentiation in renal cell carcinoma: a study of 101 cases. Am J Surg Pathol 2001, 25:275-284.

16. Brown DC, Theaker JM, Banks PM, Gatter KC, Mason DY: Cytokeratin expression in smooth muscle and smooth muscle tumors. Histopathology 1987, 11:477-486.

doi:10.1186/1756-0500-7-491

Cite this article as: Tanaka et al.: Primary leiomyosarcoma of a horseshoe kidney in a woman with Turner syndrome: a case report. BMC Research Notes 2014 7:491.

\section{Submit your next manuscript to BioMed Central and take full advantage of:}

- Convenient online submission

- Thorough peer review

- No space constraints or color figure charges

- Immediate publication on acceptance

- Inclusion in PubMed, CAS, Scopus and Google Scholar

- Research which is freely available for redistribution 